\title{
Quality of outdoor and indoor environment during the cruise of the tall ship STS Fryderyk Chopin
}

\author{
Szymon Firląg ${ }^{1, *}$ \\ ${ }^{1}$ Faculty of Civil Engineering, Warsaw University of Technology, Lecha Kaczyńskiego 16, 00-637 \\ Warszawa, Poland
}

\begin{abstract}
The aim of this paper is to present the results of measurements, on the quality of internal and external environment, carried out during the cruise of the tall ship STS Fryderyk Chopin. The cruise took place between 16th and 30th September 2017 as part of the scientific seminar of the Warsaw University of Technology (WUT) on the Wave, addressed to students of the WTU. After leaving the port of Edinburgh, crossing the North Sea, the Danish straits, stops in Copenhagen and Kołobrzeg, the tall ship reached Szczecin after two weeks. The measurements carried out on the deck included the temperature and relative humidity of the indoor air in three cabins and the men's bathroom. In two cabins, the $\mathrm{CO}_{2}$ concentration was measured additionally. The outdoor temperature, relative humidity and concentration of PM1.0, PM 2.5 and PM 10 were also measured. The obtained results allowed to assess the quality of the internal environment in accordance with the standards and to analyze the effectiveness of the mechanical ventilation system. Measurements of particulate matter have shown significant differences between outdoor air quality in the open sea and in ports or near major shipping routes. It turned out that the impact of emissions from passing ships using diesel engines is clearly visible.
\end{abstract}

\section{Introduction}

The measurements were carried out during a cruise on the STS Fryderyk Chopin tall ship as part of the scientific seminar of the WUT on the Wave. The seminar was organized by the WUT and addressed to its students. The theme of the 2017 edition was "Tools and challenges for contemporary engineers." During the seminar, students also studied the elements of a sailing ship using fiber optic sensors, electrofusion strain gauges, and accelerometers. The problem on the level of air pollutions over the seas is relatively poorly described in the literature. Some of the few results of measurements made during a voyage are presented in [1].

The aim of this article is to present observations and conclusions from the measurements of indoor air parameters and outdoor particulate matter (PM10) during a nearly half-month trip from the port of Edinburgh (GB) to the port of Szczecin (PL) in the second half of September 2017.

* Corresponding author: s.firlag@ili.pw.edu.pl 


\section{The cruise and the tall ship}

The cruise took place from the 16th to 30th of September 2017. It started in Edinburgh port in the UK and finished in Szczecin, Poland. During the cruise, the tall ship stopped in Copenhagen, Denmark, and Kołobrzeg, Poland. The measurements started on the 17th of September at 16:00 and were continued until the 29th of September at 20:00. The ship set sail in Edinburgh on the 18th of September at 14:00 and started its cruise through the North Sea in the direction of the Danish straits. After sailing through Skagerrak and Kattegat it reached Copenhagen on the 24th of September at 17:30. It stayed at this port until 8:15 on the 26th of September. Next, through the Baltic Sea, it sailed into the Kołobrzeg port in Poland at 8:00 on the 28th of September. It left the port at 18:00 on the 29th of September and sailed towards Szczecin. The conducted measurement was finished an hour after sailing out of the Kołobrzeg port.

The STS Fryderyk Chopin (Table 1) is a Polish brig-rigged training tall ship. It was designed by Polish naval architect Zygmunt Choreń, named in honour of the early to mid19th-century Polish composer Fryderyk Chopin. The ship was constructed in the Dora Shipyard, Gdańsk, Poland and launched in 1992.

Table 1. General characteristics of the STS Fryderyk Chopin.

\begin{tabular}{|c|c|}
\hline Tonnage: & $306 \mathrm{BRT}$ \\
\hline Displacement: & $400 \mathrm{tons}$ \\
\hline Length: & $181 \mathrm{ft}(55 \mathrm{~m})$ \\
\hline Beam: & $28 \mathrm{ft}(8.5 \mathrm{~m})$ \\
\hline Draft: & $13.1 \mathrm{ft}(4.0 \mathrm{~m})$ \\
\hline Propulsion: & sail, $520 \mathrm{hp}$ diesel \\
\hline Complement: & 50 \\
\hline Notes: & Sail area: $1200 \mathrm{~m}^{2}$ \\
\hline
\end{tabular}

\section{The measurements}

The measurements carried out during a cruise on the tall ship concentrated on indoor and outdoor air quality. The used approach was similar as for buildings [2, 3]. The indoor air temperature and humidity measurements were performed using NTC sensors, range $-20 \ldots+70^{\circ} \mathrm{C}$ and $0 \ldots 100 \% \mathrm{RH}$, accuracy $\pm 0.5^{\circ} \mathrm{C}$, and $\pm 3 \% \mathrm{RH}$ integrated with data loggers $175-\mathrm{H} 2$ produced by Testo company. The $\mathrm{CO}_{2}$ concentration was measured using NDIR sensors model aSENSE-D produced by SenseAir, range 0-6,000 ppm, accuracy $\pm 100 \mathrm{ppm}$ with data loggers 175 -S2 produced by Testo. The quality of indoor air was monitored in three cabins and the men's bathroom - because of the small number of sensors the scope of measurements was different. The largest cabin nr 27 was design for nine people but during the cruise occupied only by six. Three students stayed in the cabin 36 and two in 35 (Fig. 1). The measurements included:

- cabin $27-\mathrm{CO}_{2}$ concentration, air temperature and relative humidity,

- cabin 35 - air temperature and relative humidity,

- cabin $36-\mathrm{CO}_{2}$ concentration,

- men's bathroom - air temperature and relative humidity. 


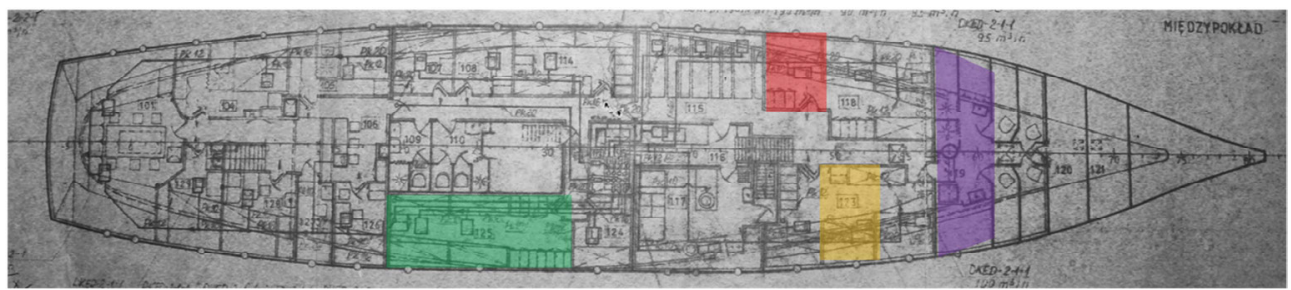

Fig. 1. Measuring device placement at the tweendecker: green - cabin 27, red - cabin 36, yellow cabin 35 and purple - men's bathroom.

In order to be able to carry out measurements in places where it is not possible to use conventional measuring stations, scientists from the Warsaw University of Technology created a prototype device for measuring PM 10, PM 2.5 and PM 1.0 dust concentrations $[4,5]$. It was built using the Arduino microcontroller, optical DFRobot dust sensor and a temperature and humidity sensor. The standard version of the device offers the possibility of immediate data transfer to the server using a modem and SIM card, however, in the case of research described in this article, due to the inability to use the mobile network at sea, the SD card was used. During the measurements, every one minute the following data was measured and saved:

- day and hour (UTC, based on data from the built-in GPS),

- geographical position (based on data from the built-in GPS),

- measured values of PM 10, PM2,5, and PM1,

- temperature and relative humidity.

The measuring device was set up at the beak of the tall ship, and the base of the foremast (Fig. 2) at the height of around $1.7 \mathrm{~m}$ over the deck. The chosen placement minimized the influence of the ship's own emissions on the measurement. All the exhausts, i.e. from the engine, and the kitchen were behind the device. The ship mostly sailed into the wind or with a side wind, thus leaving the device freely perfused by air coming straight from the sea. Most of the cruise was sailed, and the engine was used periodically. The engine and power generator exhaust were emitted through a chimney placed on the mainmast at the waist. The chimneys height is $32 \mathrm{~m}$ from the deck.

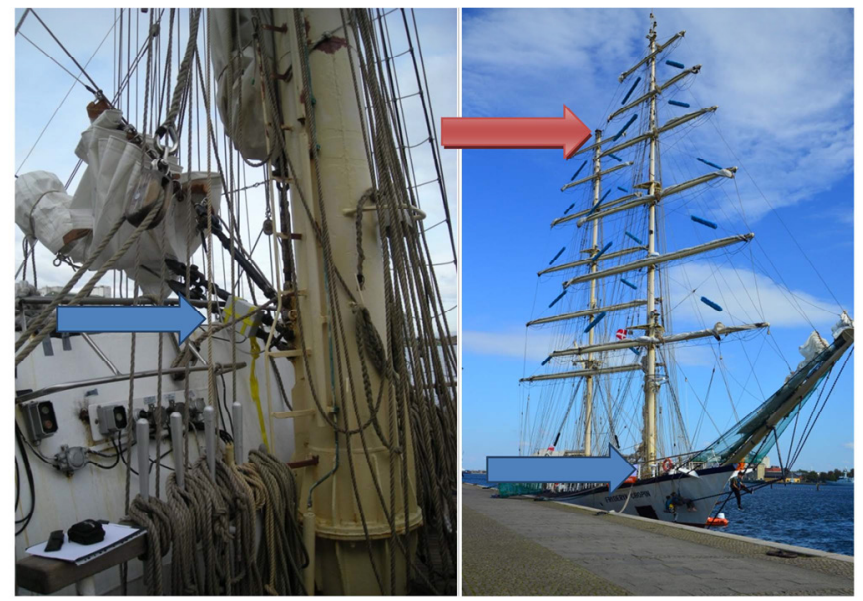

Fig. 2. Measuring device placement (blue arrow) at the base of the foremast at the beak of the tall ship, engine chimney (arrow red). 


\section{Indoor environment}

Evaluation of the indoor environment was based on categories and criteria according to ISO EN 7730 and EN 15251 (Table 2). The estimation of the percentage of time in each category was made for each cabin and the bathroom.

Table 2. Description of the applicability of the categories used in EN 15251.

\begin{tabular}{|c|c|}
\hline Category & Explanation \\
\hline I & $\begin{array}{c}\text { High level of expectation and is recommended for spaces occupied by very sensitive } \\
\text { and fragile persons with special requirements like the handicapped, sick, very young } \\
\text { children and elderly persons }\end{array}$ \\
\hline II & Normal level of expectation and should be used for new buildings and renovations \\
\hline III & An acceptable, moderate level of expectation and may be used for existing buildings \\
\hline IV & Values outside the criteria for the above categories. This category should only be \\
accepted for a limited part of the year
\end{tabular}

The outdoor temperature changed over the cruise form $9.9^{\circ} \mathrm{C}$ (port Kołobrzeg) to $20.7^{\circ} \mathrm{C}$ (port Copenhagen). The temperature distribution on the ship deck, in accordance with the standard EN15251, is given in Table 3. The evaluation of indoor temperature shows that the best conditions are in cabin 35 (category I and II over $80 \%$ of the time). Also in cabin 27 the temperatures are most of the time in category I and II. Only in the men's bathroom the temperatures are much lower. This is probably caused by a lack of radiators and the location of the bathroom on the bow of the tall ship.

Table 3. Quality of thermal environment in \% of time in four categories - temperature.

\begin{tabular}{|c|c|c|c|c|}
\hline Category & I & II & III & IV \\
\hline $\begin{array}{c}\text { Temperature } \\
\text { range }\end{array}$ & $21.0-23.0^{\circ} \mathrm{C}$ & $\begin{array}{c}20.0-21.0^{\circ} \mathrm{C} \\
\text { and } \\
23.0-24.0^{\circ} \mathrm{C}\end{array}$ & $\begin{array}{c}19.0-20.0^{\circ} \mathrm{C} \\
\text { and } \\
24.0-25.0^{\circ} \mathrm{C}\end{array}$ & other \\
\hline cabin 27 & $32.0 \%$ & $44.6 \%$ & $16.6 \%$ & $6.7 \%$ \\
\hline cabin 35 & $54.3 \%$ & $28.3 \%$ & $12.1 \%$ & $5.3 \%$ \\
\hline men's bathroom & $11.7 \%$ & $35.6 \%$ & $31.5 \%$ & $21.2 \%$ \\
\hline
\end{tabular}

The Fig. 3. shows the indoor air temperature changed a lot during the cruise. It was over $27^{\circ} \mathrm{C}$ in cabin 27 on the 18 th of September and below $16^{\circ} \mathrm{C}$ in the men's bathroom on the 30 th. The wide range of changes shows that there is no temperature control. It depends on outdoor conditions, internal heat gains and the operation of the ventilation system. The ship has an air heating system that was off during the cruise. 


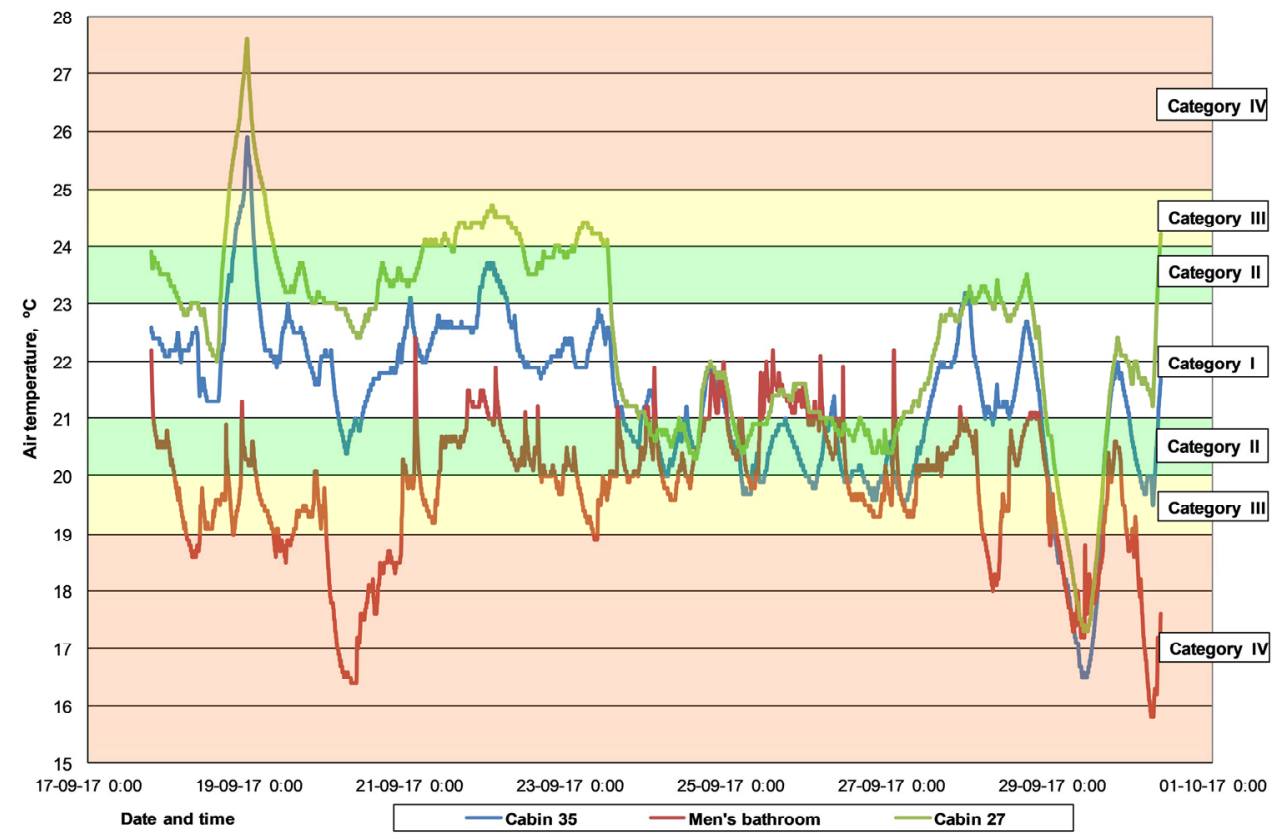

Fig. 3. Change of indoor air temperature in cabins and men's bathroom of the tall ship.

The outdoor relative humidity changed over the cruise from $60.3 \%$ (port Edinburgh) to $99.9 \%$ (North Sea). Unfortunately the outdoor RH sensor had broken in the middle of the cruise. It was probably the influence of salt from the sea water. The RH distribution on the ship deck in accordance with the standard EN15251 is given in Table 4. The evaluation of indoor RH shows that the best conditions are in cabin 27 (the large one occupied by 6 people). Over $60 \%$ of the time the RH is category I and II. In the small cabin 35 the situation is worse because during $25 \%$ of time, the values are outside the criteria. This is caused probably by a higher density of occupants and lower air temperatures. The RH outside the criteria was measured in the men's bathroom over $55 \%$ of time.

Table 4. Quality of thermal environment in \% of time in four categories - RH.

\begin{tabular}{|c|c|c|c|c|}
\hline Category & I & II & III & IV \\
\hline $\begin{array}{c}\text { Temperature } \\
\text { range }\end{array}$ & $30-50 \%$ & $\begin{array}{c}25-30 \% \text { and } \\
50-60 \%\end{array}$ & $\begin{array}{c}20-25 \% \text { and } \\
60-70 \%\end{array}$ & other \\
\hline cabin 27 & $12.7 \%$ & $50.4 \%$ & $29.2 \%$ & $7.6 \%$ \\
\hline cabin 35 & $3.5 \%$ & $28.9 \%$ & $42.3 \%$ & $25.5 \%$ \\
\hline men's bathroom & $0.0 \%$ & $11.0 \%$ & $34.3 \%$ & $54.8 \%$ \\
\hline
\end{tabular}

The Fig. 4. clearly shows that as a result of moisture gains (during the showers or cleaning), the level of RH increases quickly in the bathroom reaching sometimes $100 \%$. The level of humidity drops quickly also, which shows that the ventilation is quite effective. The main reason of high $\mathrm{RH}$ is the low temperature in the bathroom. During the majority of the cruise it is below the temperature in the cabins. Only between the 24th and 27 th of September the temperatures are similar, and as result the RH in the cabins increases 
to the level as in the bathroom. A high level of humidity in the bathroom can cause mold growth [6] and corrosion of the ship's structure. The difference between cabin 27 and 35 is caused probably by a difference in occupation density- more people per $\mathrm{m}^{2}$ were staying in cabin 35 and the air exchange rate was greater.

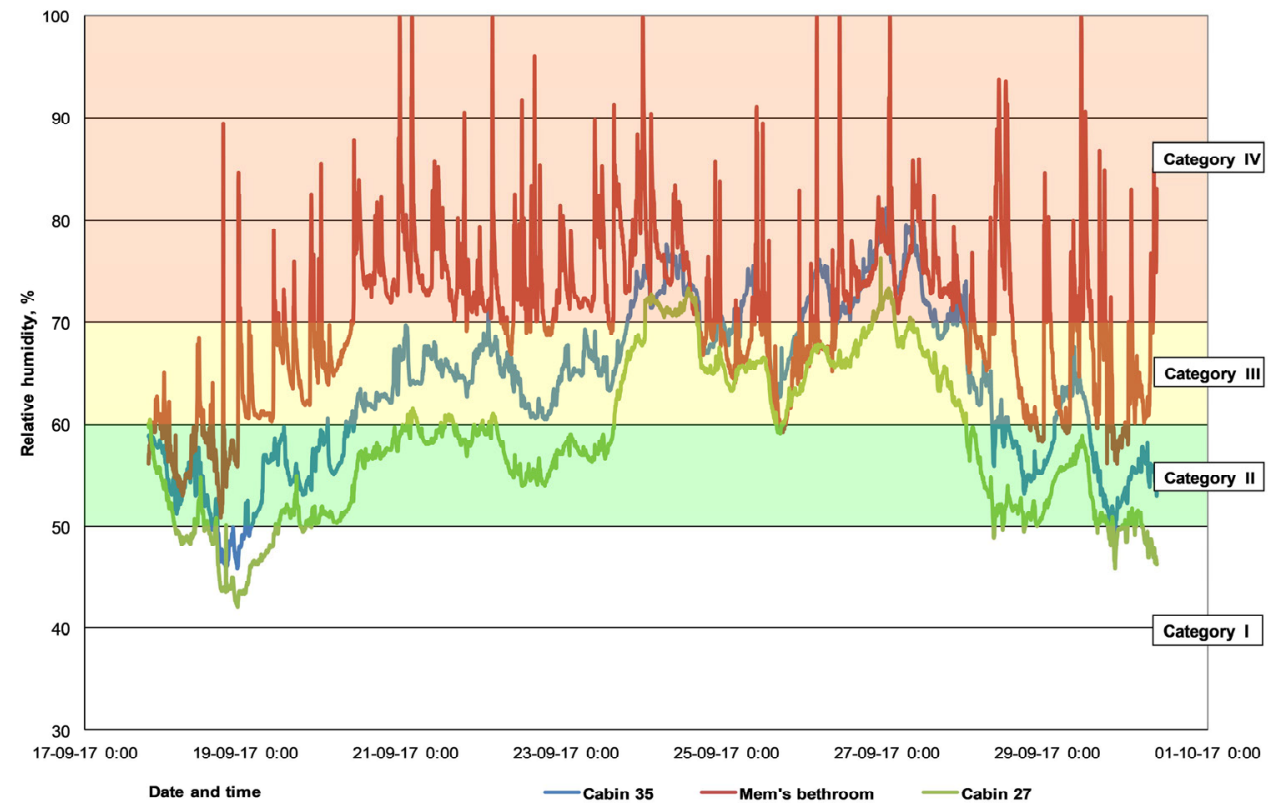

Fig. 4. Change of indoor relative humidity in cabins and men's bathroom of the tall ship.

The assessment of indoor air quality was based on the indirect approach of measuring $\mathrm{CO}_{2}$ concentrations. It was assumed that people are the main pollution sources in the building. The measurements were made during the cruise in two cabins. Recommended $\mathrm{CO}_{2}$ concentrations above the outdoor concentration (Table 5) from EN 15251 were used to evaluate the indoor air quality in the cabins. The outdoor $\mathrm{CO}_{2}$ concentration was measured at the beginning and end of the cruise. Because it was not possible to perform constant outdoor measurements (only two devices available) it was assumed that the $\mathrm{CO}_{2}$ concentration will be constant. The accuracy of the sensor $\pm 100 \mathrm{ppm}$ can affect the results.

Table 5. Quality of thermal environment in $\%$ of time in four categories $-\mathrm{CO}_{2}$ above outdoors.

\begin{tabular}{|c|c|c|c|c|}
\hline Category & I & II & III & IV \\
\hline $\begin{array}{c}\text { Corresponding } \\
\begin{array}{c}\mathrm{CO}_{2} \text { above } \\
\text { outdoors }\end{array}\end{array}$ & below $350 \mathrm{ppm}$ & $350-500 \mathrm{ppm}$ & $500-800 \mathrm{ppm}$ & above $800 \mathrm{ppm}$ \\
\hline cabin 27 & $33.4 \%$ & $50.3 \%$ & $16.1 \%$ & $0.2 \%$ \\
\hline cabin 36 & $42.5 \%$ & $47.2 \%$ & $9.7 \%$ & $0.6 \%$ \\
\hline
\end{tabular}

The results in Table 5. and Fig. 5. show that the air quality was very good. In cabin 27 almost $85 \%$ and in cabin 36 almost $90 \%$ of time the concentration was in category I and II. The scale of value variation is rather small. Some higher concentrations can be seen for a short time but this is probably the results of the student's tests (checking if the device is 
working). It can be also observed that from the 23rd of September the concentrations are clearly smaller. This is a result of change in mechanical ventilation operation. The system was equipped in two air intakes - one outside and one inside. At the beginning of the cruise the inside air intake was open - the system was working in recalculation mode. From the 23rd it was closed. As a result the $\mathrm{CO}_{2}$ concentration in the cabins decreases. The effect of change can be also seen on the Fig. 3. - temperatures in the cabins are dropping down as more outdoor, cold air is supplied. The extreme value-peaks $(>1,500 \mathrm{ppm})$ probably represent the sensor checking by the students - it was possible to see the result on the display.

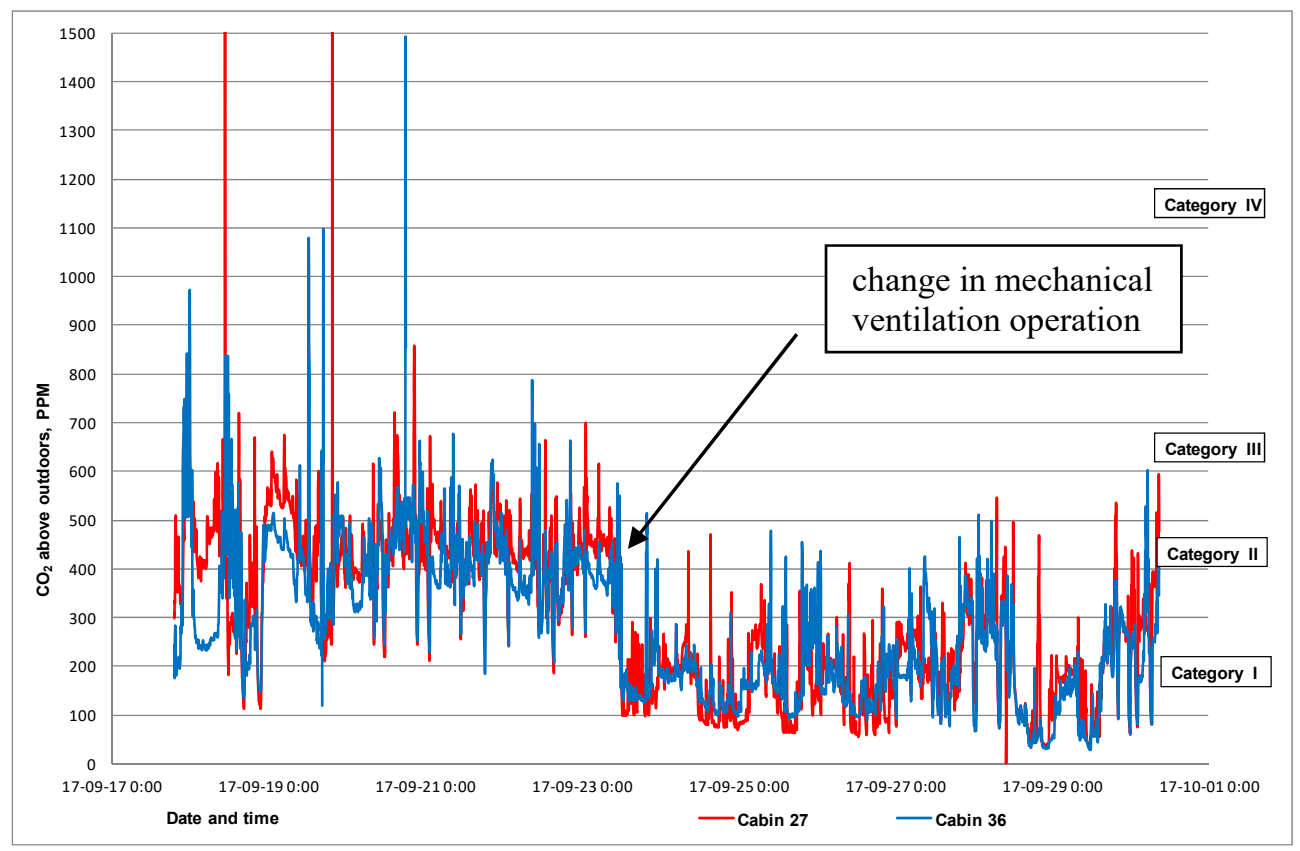

Fig. 5. Change of $\mathrm{CO}_{2}$ concentration above outdoors in cabins of the tall ship.

\section{Outdoor environment}

The research conducted during the cruise of the STS Fryderyk Chopin tall ship gave the possibility of determining the concentration of dust particles on the sea, as well as in the ports. Due to the use of sails as the main drive, the ship's own emission was minimized. Also, the ship's route had covered areas with both a dense and small intensity of maritime traffic. This has allowed for a big variability of results. 


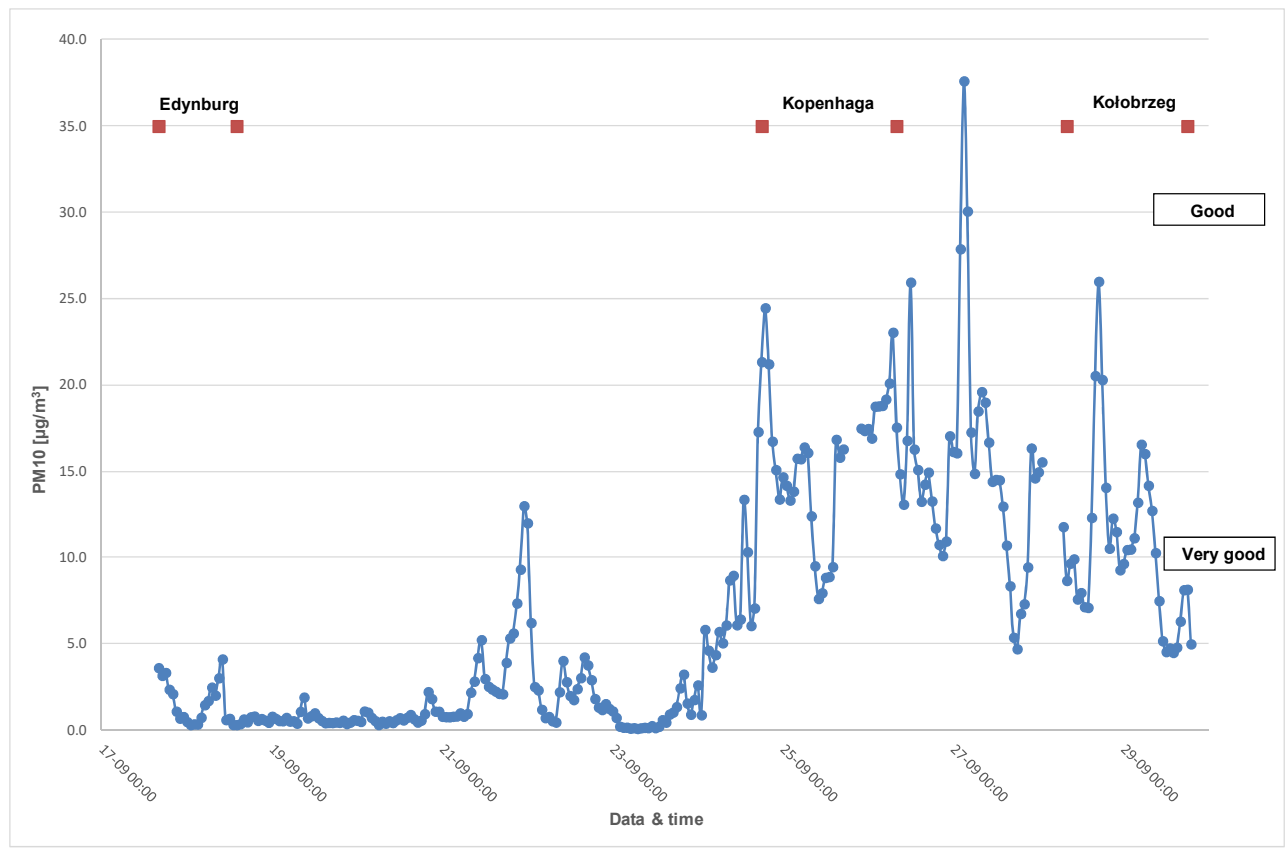

Fig. 6. Average hourly concentration of PM 10 particles $\left[\mu \mathrm{g} / \mathrm{m}^{3}\right]$ throughout the whole cruise with marked stops in ports.

Recommended PM 10 concentrations from Chief Inspectorate for Environmental Protection [7] were used to evaluate the outdoor air quality (Fig. 6). If the average hourly concentration of PM 10 particles is below $20 \mu \mathrm{g} / \mathrm{m}^{3}$ the air quality is very good, and between $20-60 \mu \mathrm{g} / \mathrm{m}^{3}$ is good. The maximum measured concentration was $37.6 \mu \mathrm{g} / \mathrm{m}^{3}$ and the minimum $0,1 \mu \mathrm{g} / \mathrm{m}^{3}$. During $95 \%$ of the cruise the quality of the outdoor air was very good. The WHO limit for PM 10 concentrations is $50 \mu \mathrm{g} / \mathrm{m}^{3}$.

The results have shown better than expected quality of air in the region of Edinburgh, compared to many different cities and ports in Europe. There were many areas on the North Sea with good air quality - starting from the Scottish coast to Danish or Swedish coasts, sometimes the measuring device did not register any suspended dust presence. The outdoor air was very clean in an area around the entrance to the Skagerrak Strait. The major influence on the good air quality was caused by high wind speeds. The particle concentration was relatively low up until the Copenhagen port. 


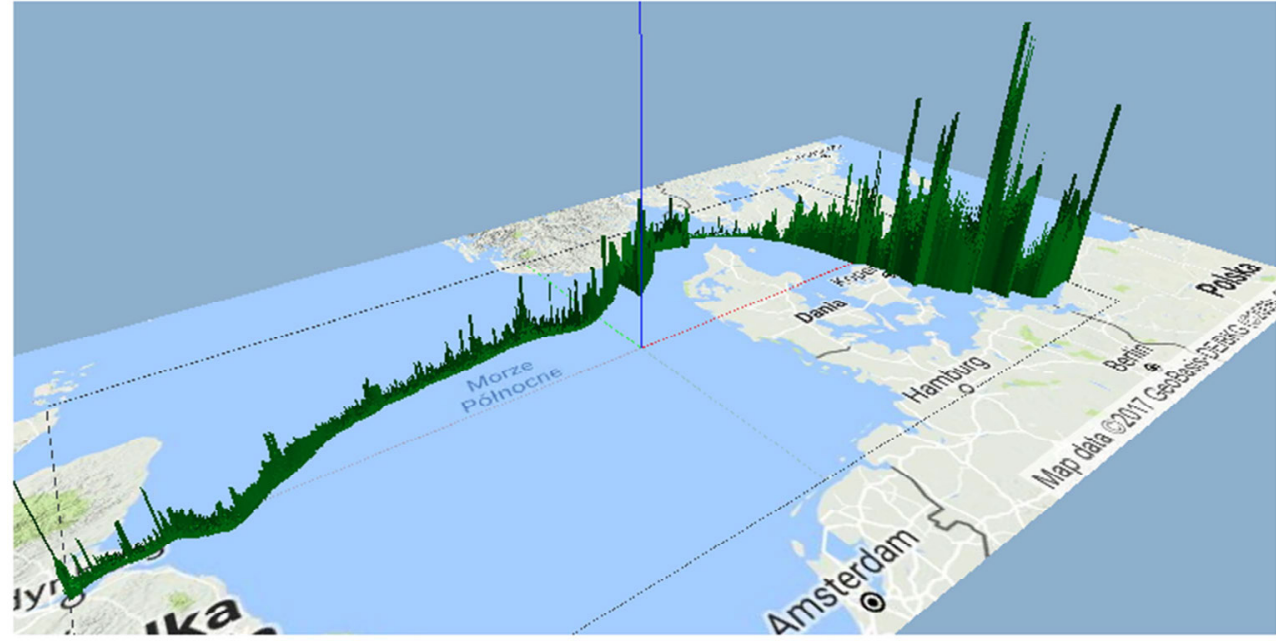

Fig. 7. Average hourly concentration of PM 10 particles $\left[\mu \mathrm{g} / \mathrm{m}^{3}\right]$ throughout the whole cruise with marked stops in ports.

The values of changes in PM 10 concentration in Copenhagen are characterized by typical, city fluctuations (this means min. around noon, max. afternoon). The Baltic Sea (Fig. 7) region was characterized by much a higher level of pollution than the North Sea, or even the Copenhagen port. It is hard to point at land sources of emission as the main element of air pollution on the sea - the highest temporary pollution was registered at a location further from the land, with values increasing as the ship approached.

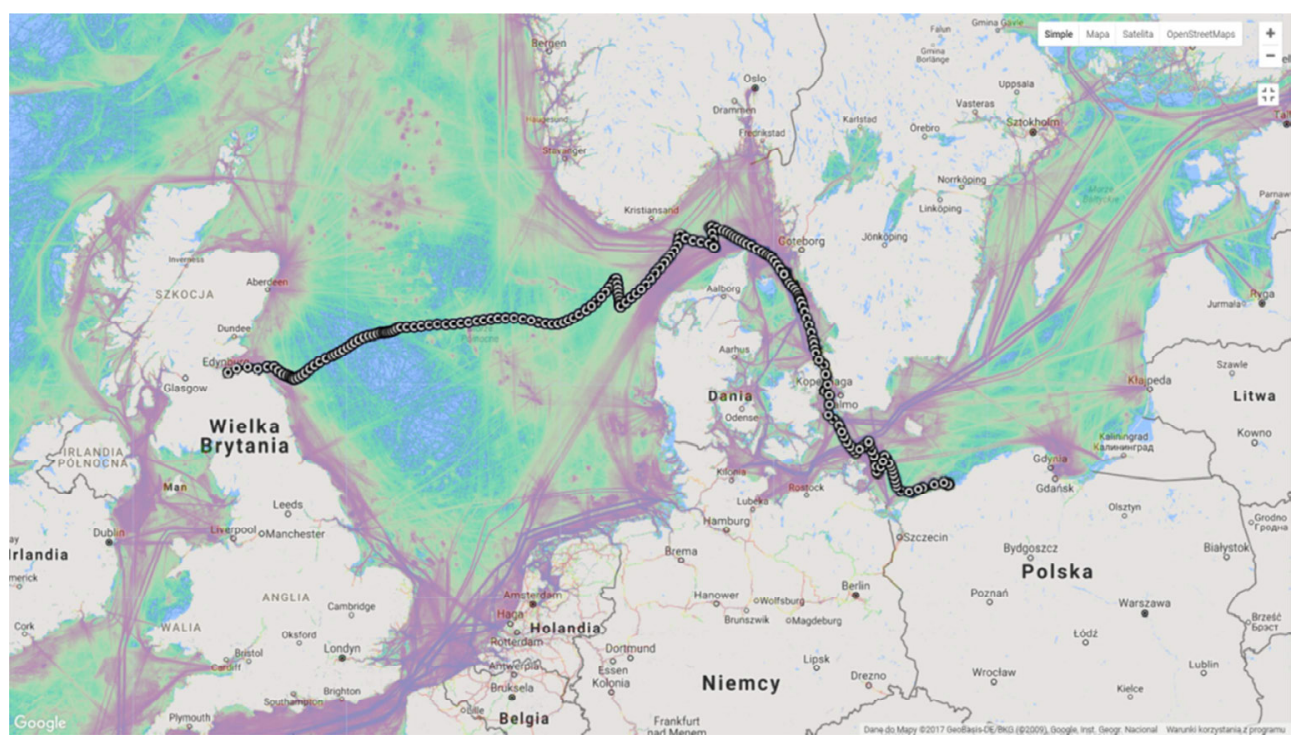

Fig. 8. Tall ship path on a background showing sail intensity of ships and main shipping lanes (source: marine traffic).

Shipping lane analysis, performed via the marine traffic service, shows that the tall ship was near the main lane attended by multiple ships (Fig. 8). Based on the comparison performed above we could risk the following hypothesis. The vast majority of the cruise 
route, in the events when the ship was nearby land, happened in the Danish straits and the Baltic Sea, wherein principle it's much "narrower" than in the full North Sea. The high level of pollution could have been influenced by land sources, however, as it is shown in the above Figure and, in such places the route of the tall ship was close to, crossing or even following, the highly attended shipping routes. One gets the impression that the sources of pollution coming from ships "covered" emissions coming from land (except port entrances, which were present in bigger or smaller cities), and they were the main source of pollution on the sea. A confirmation of such a claim can come from the fact that places were recorded at a considerable distance from land - about $200 \mathrm{~km}$ and $400 \mathrm{~km}$, where there were higher concentrations, and they could not have come from land-based emissions. The source of emission was in this case probably the ships using diesel or marine oil.

\section{Conclusions}

The research conducted during the cruise of the STS Fryderyk Chopin tall ship gave the possibility of determining the quality of indoor and outdoor environment. The measurements on the deck included the temperature and relative humidity of the air and $\mathrm{CO}_{2}$ concentration. The obtained results allowed assessing the quality of the internal environment in accordance with the standards and analysing the effectiveness of the mechanical ventilation system. The outdoor air quality was analysed from the perspective of the concentration of dust particles (PM 10) on the sea, as well as in the ports. Due to the use of sails as the main drive, the ship's own emission was minimized. Also, the ship's route had covered areas with both a dense and small intensity of maritime traffic. The main conclusions are as follows:

- The quality of the indoor air $\left(\mathrm{CO}_{2}\right.$ concentration) during the cruise was very good. It shows that the air exchange rate of mechanical ventilation seems to be appropriate.

- A large variation of the internal air temperature and large differences between rooms show that the heating system is ineffective.

- High relative humidity, especially in the men's bathroom, was noted. A decrease of it can be achieved thanks to an increase of the temperature in the bathroom or dehumidification of supply air.

- The main source of air pollution on the sea is the passing of ships. The values of concentration of dust particles in the region of shipping lanes are several times higher than in different regions of the same reservoir.

- The pollution from the ships can create a dust suspension that is considered relatively high, even in the case of land areas, where there are many more pollution sources (Baltic Sea example).

\section{References}

1. C. Schembari, MC Bove, E. Cuccia, F. Cavalli, J. Hjorth, D. Massab, S. Nava, R. Udisti,P. Prati, Atmos Environ, 98, 510-518 (2014)

2. S. Firląg, Czasopismo Techniczne, 8, 3-B, (2014)

3. A. Węglarz, P. Narowski, Proceedings of the Building Simulation, 14-16 (2011)

4. M. Rogulski, Pol. J. Environ. Stud. 27, No. 4, 1699-1705 (2018)

5. M. Rogulski, Energy Procedia 128, 437-444 (2017)

6. A. Kaliszuk-Wietecka, Budownictwo zrównoważone - Wybrane zagadnienia z fizyki budowli, (PWN, 2017)

7. http://powietrze.gios.gov.pl/pjp/current 